\title{
BMJ Open What keeps family physicians busy in Portugal? A multicentre observational study of work other than direct patient contacts
}

\author{
Mónica Granja, ${ }^{1}$ Carla Ponte, ${ }^{2}$ Luís Filipe Cavadas $^{3}$
}

To cite: Granja M, Ponte C, Cavadas LF. What keeps family physicians busy in Portugal? A multicentre observational study of work other than direct patient contacts. BMJ Open 2014;4:e005026.

doi:10.1136/bmjopen-2014005026

- Prepublication history and additional material is available. To view please visit the journal (http://dx.doi.org/10. 1136/bmjopen-2014-005026).

Received 10 February 2014 Revised 15 May 2014 Accepted 23 May 2014

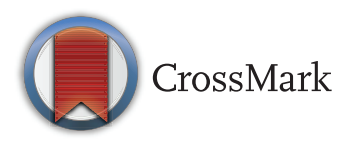

${ }^{1} \mathrm{~S}$. Mamede de Infesta Health Centre, Matosinhos Local Health Unit, Matosinhos, Portugal

${ }^{2}$ Porta do Sol Family Health Unit, Matosinhos Local Health Unit, Matosinhos, Portugal

${ }^{3}$ Lagoa Family Health Unit, Matosinhos Local Health Unit, Matosinhos, Portugal

\section{Correspondence to} Dr Mónica Granja; monica.granja@ulsm. min-saude.pt

\section{ABSTRACT}

Objectives: To quantify the time spent by family physicians (FP) on tasks other than direct patient contact, to evaluate job satisfaction, to analyse the association between time spent on tasks and physician characteristics, the association between the number of tasks performed and physician characteristics and the association between time spent on tasks and job satisfaction.

Design: Cross-sectional, using time-and-motion techniques. Two workdays were documented by direct observation. A significance level of 0.05 was adopted.

Setting: Multicentric in 104 Portuguese family practices. Participants: A convenience sample of FP, with lists of over 1000 patients, teaching senior medical students and first-year family medicine residents in 2012, was obtained. Of the $217 \mathrm{FP}$ invited to participate, 155 completed the study.

Main outcomes measured: Time spent on tasks other than direct patient contact and on the performance of more than one task simultaneously, the number of direct patient contacts in the office, the number of indirect patient contacts, job satisfaction, demographic and professional characteristics associated with time spent on tasks and the number of different tasks performed, and the association between time spent on tasks and job satisfaction.

Results: FP ( $n=155)$ spent a mean of $143.6 \mathrm{~min} /$ day $(95 \% \mathrm{Cl} 135.2$ to 152.0$)$ performing tasks such as prescription refills, teaching, meetings, management and communication with other professionals $33.4 \%$ of their workload). FP with larger patient lists spent less time on these tasks $(p=0.002)$. Older FP $(p=0.021)$ and those with larger lists $(p=0.011)$ performed fewer tasks. The mean job satisfaction score was 3.5 (out of 5). No association was found between job satisfaction and time spent on tasks.

Conclusions: FP spent one-third of their workday in coordinating care, teaching and managing. Time devoted to these tasks decreases with increasing list size and physician age.

\section{INTRODUCTION}

The content of Family Medicine/General Practice (FM/GP) in Portugal has changed

\section{Strengths and limitations of this study}

- This is the first national study of tasks other than direct patient contact by family physicians.

- Participating physicians are representative of Portuguese family physicians (FP) in terms of age and geographic location.

- Only $10(4.7 \%)$ FP refused to participate.

- The use of direct observation by external observers yields more accurate data than self-reporting or other methods.

- Participation was not random and the sample size was smaller than desirable due to the difficulty in recruiting students and residents for data collection.

- This study included only those FP involved in teaching students and residents

- Data collection by multiple observers can introduce inter-observer bias.

since the creation of the specialty 30 years ago. The National Health System (NHS) has set new priorities, the population is ageing, there is greater complexity of care, medical school and FM/GP residency enrolment has increased, and new technologies are available. The tasks family physicians (FP) must perform extend beyond direct patient contact in the office. These include maintaining electronic clinical records, referrals, prescription refills, follow-up of diagnostic tests, telephone calls and e-mail with patients and families, ${ }^{1-5}$ collaboration with other professionals, performance analysis, practice management, teaching and research. ${ }^{6} \quad 7$ Many of these tasks optimise the time spent in office visits, maximise patient access and continuity of care, and often improve coordination of care, which are core attributes of FM/GP. ${ }^{8}$ They also promote the development of FM/GP as a scientific discipline. Other tasks arise from bureaucratic demands of the healthcare system. 
Characterising the work of the FP other than direct patient contact is important because of the 'invisibility' of this work. Lack of protected time for these activities may result in increased physician stress and decreasing motivation to perform them. The difficulty in recording some of these tasks may not only have effects on continuity of care but may also have a medico-legal fallout.

The first Portuguese study on this subject was published in 2011. Indirect patient care tasks comprised a mean of $2 \mathrm{~h}(23 \%)$ of the FP workday in the Matosinhos Local Health Unit. ${ }^{10}$ This study included only a small sample of doctors in one district. Data were collected by self-report in real time by participating FP, which did not allow for the quantification of time spent on each specific task.

Studies conducted in the USA ${ }^{11-17}$ found that medical tasks in addition to direct patient contact account for an important part of the workload in primary care.

Portuguese primary healthcare provides universal access to patients in the NHS. FP complete a 4-year specialtytraining programme. They act as gatekeepers for secondary and hospital care. Most general practices have 5-10 FP working in a group and most doctors care for a list of 1500-1900 patients. The FP/nurse ratio averages $1: 1$, the $\mathrm{FP} /$ clerical staff ratio averages 2:1 and there is limited access to social workers, nutritionists and psychologists. FP are responsible for family planning, follow-up of child development, surveillance of low risk pregnancies, chronic disease management and care of the elderly. In-hospital work is not part of the task of Portuguese FP. The use of electronic prescription software and electronic medical records are mandatory in the NHS. More than $90 \%$ of general practices use the same software while hardware, bandwidth and browsing speed are highly variable across practices. In classic general practices, called Personalised Health Care Units, professionals are allocated by the Ministry of Health and paid a fixed salary. A recent development as a result of primary healthcare reform has been the development of Family Health Units (FHU). FHU are formed by a voluntary association of physicians, evaluated with a set of performance indicators (determined by the Ministry of Health) and paid a salary based on capitation, with a mix of fee-for-service and pay-for-performance bonuses.

The objectives of this study were to determine, for FP working in Portugal:

- The time spent performing tasks other than direct patient contact

- The time spent on each task other than direct patient contact and on performance of simultaneous tasks

- The total number of different tasks performed

- The number of daily patient contacts and of non face-to-face contacts recorded

- Job satisfaction

- The association between physician characteristics and the time spent on tasks other than direct patient contact, the number of different tasks performed and the time spent performing simultaneous tasks

- The association between time spent on tasks and job satisfaction.

\section{METHODS}

A descriptive cross-sectional study, with an analytic component, was conducted in 2012. The participants were FP working in Portuguese family practices. Physicians with a patient list size of less than 1000 patients were excluded. Data were collected by medical students and residents who served as external observers. A convenience sample was obtained including FP who tutored medical students in the first semester 2012. As the recruitment was smaller than expected, by June 2012, data collection was extended until 31 December 2012, and first-year family medicine residents and their tutors were also invited to participate.

This was a non-random sample. The sample size was set at 620 participants based on the total number of medical students in the last 2 years of the eight Portuguese medical schools who would rotate in family practices in the first semester of 2012. No published studies were found referring to recruitment ratios of medical students as research observers.

The FM/GP departments of the eight Portuguese medical schools and the coordinators of five Portuguese FM/GP regional residency programmes were approached and asked to help recruit medical students and residents as voluntary observers. Medical schools and residency programmes were asked to provide a list of those FP chosen as tutors for their students and residents. The names and workplace only were provided and no additional data on potential participants were available. FP teaching medical students and residents willing to collaborate were contacted by researchers by phone or e-mail or by the medical students and residents themselves. FP willing to participate received the study protocol and provided written informed consent.

Each FP chose two working days for the study, preferably consecutive days with at least 14 working hours in practice.

Using time-and-motion techniques, ${ }^{18} 19$ medical students and residents acting as observers shadowed their tutors and collected data on the tasks they performed other than direct patient contact and recorded the time they spent on each task. Researchers prepared a data collection grid based on previous studies ${ }^{11}{ }^{12}$ and adapted after experience gained in an exploratory study. ${ }^{10}$ Observers recorded the start and end time of each task in real time, rounding times to the nearest minute, using a digital clock. Where two or more tasks were performed simultaneously, they were both recorded including the start and end time of each task. The number of direct patient contacts, non face-to-face contacts, demographic and professional characteristics of physicians and ratings of how typical the workday was were also recorded.

If a portion of the FP workday was not observed or registered, it was coded as 'lost data'. Data sets with losses longer than half the total time under observation were excluded. If, owing to the educational requirements of the observers, an entire half-day was lost for 
observation, the remaining period was considered the day under observation and data were included accordingly. One minute was counted for tasks starting and ending in the same minute and for tasks whose duration could not be established (usually for lack of an end time). Time spent performing tasks of different categories recorded together was allocated in equal parts.

Data collection forms were returned by mail or hand delivered to the observers' schools. When data were delivered with potentially retrievable missing data (such as demographic data, numbers of patient contacts or job satisfaction scores), the observer or the FP were contacted to complete them.

Time variables were counted in minutes, including the time allocated to tasks and to personal activities directly recorded by the observer, and with time for direct patient contact indirectly estimated. The observer classified tasks other than direct patient contacts using a taxonomy developed by the researchers (see online supplementary appendix I). In cases of doubt, tasks were described verbally and subsequently classified by researchers. The numbers of direct patient contacts in office visits and non face-to-face contacts recorded in the medical record on each study day were provided by FP based on their electronic records. The typical nature of each workday was evaluated subjectively by the FP using a Likert scale ( 1 being 'completely atypical' and 5 'completely typical'). FP job satisfaction was assessed by the self-administered 'Quality pentagon job satisfaction questionnaire' of Biscaia (used with permission). ${ }^{20} 21$

Collected data were anonymised and entered in Microsoft Excel and analysed using STATA 10.1 software. Frequencies, means, medians, SD and CIs were calculated. The Student's $\mathrm{t}$ test was used to compare the means of two independent variables and ANOVA was used for more than two variables. A hierarchical regression model was built to study the association between two interval variables, considering the time of data collection.

Observer bias was minimised using debriefing sessions for students participating in data collection, a portable paper script standardising procedures and task categorisation provided to each collaborator, supervision of students and residents in real time, and selection of workdays observed in the middle of students' rotation to minimise the Hawthorne effect. Each data set was read and codified separately twice. One researcher (CP or LC) codified each data set once. The senior researcher (MG) read and codified all data sets, to assure homogeneity.

No identifying or clinical data were collected on patients for this study. Students and residents attended only the clinic sessions they would normally attend during their rotation or residency. Each FP provided informed consent for participation in the study and all were guaranteed confidentiality of personal data, data anonymisation and the non-disclosure of any individual or practice results. The study was funded by a grant from the Ministry of Health. Two independent primary care ethical review boards approved the study protocol.

\section{RESULTS}

All FM/GP regional residency programme coordinators and seven of eight medical schools cooperated in recruiting student observers for the study. A total of 1321 potential observers were approached, including 890 medical students in the final 2 years of medical school and 431 first-year FM/GP residents. Data were collected by 135 students and 18 residents (153 observers) from 155 FP. Two residents collected data from two FP each.

In total, $217 \mathrm{FP}$ were invited to participate in the study requiring direct observation of two workdays. Ten doctors $(4.6 \%)$ refused to participate. Six doctors were observed but their data were excluded from the analysis (table 1). Data from $46 \mathrm{FP}$ were not received. For 39 of these, the reason for the missing data was not determined as the student observers were not reachable for an explanation.

In the final study sample of $155 \mathrm{FP}, 70.3 \%$ (109) were women. Data on participants' age, years of practice as an FP and list size are given in table 2. Data on age and years of practice were missing for five participants and data on list size were missing for four participants.

Most participating FP worked in practices in two regions: Lisbon and the Tagus Valley Region (38.7\%) and the Northern Region (38.7\%) (table 3). The majority worked in FHU, were salaried employees, with the collective public service contract working $42 \mathrm{~h}$ /week (table 3).

Participating FP worked in 104 different practices in 14 of the 18 districts in the Portuguese mainland and from one of two island regions. Porto, Lisbon, Setúbal, Braga and Coimbra were the districts with the greatest representation (figure 1).

\begin{tabular}{|c|c|c|}
\hline Participating physicians & $\mathbf{n}$ & $\%$ \\
\hline Invited & 217 & \\
\hline Refused & 10 & 4.6 \\
\hline Excluded & 6 & 1.1 \\
\hline Had not completed training & 2 & \\
\hline Patient list $<1000$ patients & 2 & \\
\hline$>50 \%$ data loss & 2 & \\
\hline Undelivered & 46 & 21.2 \\
\hline Observer withdrew & 4 & \\
\hline Tutor illness & 1 & \\
\hline No fixed tutor & 1 & \\
\hline Data collection form lost & 1 & \\
\hline Unknown cause & 39 & \\
\hline Delivered data & 155 & 71.4 \\
\hline
\end{tabular}


Table 2 Demographic and professional characteristics of FP

\begin{tabular}{llrrrrr}
\hline & $\mathbf{n}$ & Mean & Median & Minimum & Maximum & SD \\
\hline Age & 150 & 48.8 & 54.0 & 26 & 62 & 10.18 \\
Years as FP & 150 & 19.0 & 24.5 & 1 & 10.66 \\
Patient list size & 151 & 1771.4 & 1773.0 & 1090 & 2300 & 189.90 \\
\hline FP, family physicians. & & & & &
\end{tabular}

Data were not available on demographic or professional characteristics of FP who refused to participate, or whose data were not delivered (table 1).

Medical activities were recorded for a total of 310 workdays. The 2 days studied for each FP were successive weekdays in $68.4 \%$ of cases. The median score for 'typicality' of the workday was 4 on a scale of 1 to 5 $(n=293$ days, first quartile $=1$ and third quartile $=5)$.

The mean length of the FP workday (time between arriving at work and leaving the practice) exceeded $8 \mathrm{~h}$. An average of $430.1 \mathrm{~min} /$ day was spent on effective work, with $278.2 \mathrm{~min}$ allocated to face-to-face direct patient contacts (excluding any interruptions to perform other activities) and $143.6 \mathrm{~min}$ to perform tasks other than direct patient contact (table 4). Doctors saw a mean of 19.1 patients/day and spent $15.9 \mathrm{~min} /$ patient.

A mean of $8.3 \mathrm{~min} /$ day were spent on house calls and other external work. A daily mean of 57.6 min was spent on personal activities (snacks, hygiene, socialising, personal calls). The observers were unable to observe a mean of $11.0 \mathrm{~min} /$ day. Tasks other than direct patient

\begin{tabular}{lrr}
$\begin{array}{l}\text { Table } 3 \text { Professional features of participating family } \\
\text { physicians ( } \mathrm{n}=155)\end{array}$ & \multicolumn{1}{l}{ N } \\
\hline & & \\
\hline Region & 60 & 38.7 \\
Lisbon and Tagus Valley & 60 & 38.7 \\
North & 14 & 9.0 \\
Centre & 13 & 8.4 \\
Alentejo & 7 & 4.5 \\
Algarve & 1 & 0.6 \\
Madeira & & \\
Practice type & 114 & 73.6 \\
Family Health Unit & 41 & 26.4 \\
Personalised Health Care Unit & & \\
Contract type & 133 & 85.8 \\
Collective public contract & 13 & 8.4 \\
Individual public contract & 9 & 5.8 \\
Unknown & & \\
Weekly schedule (contract hours) & 83 & 53.6 \\
$42 \mathrm{~h}$ & 47 & 30.3 \\
$40 \mathrm{~h}$ & 17 & 11.0 \\
35 h & 2 & 1.3 \\
Other & 6 & 3.9 \\
Unknown & &
\end{tabular}

contact represented $33.4 \%$ of the effective working time observed (table 5).

A mean of $10.8( \pm 3.40)$ different tasks was performed daily (minimum 2, maximum 24). The performance of more than one task simultaneously was observed during $3.7 \mathrm{~min} /$ day $(2.6 \%$ of the total time spent with the tasks).

On average, non-contact time spent daily on tasks directly related to patients $(73.0 \mathrm{~min})$ was similar to noncontact time spent with tasks unrelated to patients (74.3 min). The non-contact tasks that accounted for most of the FP workday were prescription refills, student and resident teaching, practice meetings, practice management, administrative or clinical communication with other professionals and work preparation (table 6). Other non-contact tasks were related to laboratory, imaging and other tests, visits from pharmaceutical representatives, phone calls to and from patients, referrals and attention to computer malfunctions. The least amount of time was spent on e-mails to and from patients, research, case study and performance monitoring.

Tasks most often performed simultaneously overlap the most common tasks performed.

A mean of 25 contacts/day were recorded in the electronic medical record. These included 19 direct patient contacts in the office and 6 non face-to-face contacts. Data on the number of direct and indirect contacts recorded were missing in 26 and 46 of the 310 days studied, respectively.

Global job satisfaction scores averaged 3.5 on a scale from 1 (minimal satisfaction) to 5 (maximal satisfaction). The dimension 'pressure and demands at work' accounted for the lowest satisfaction score (2.5) and 'interpersonal relations and autonomy' accounted for the highest score (4.2) (table 7).

No association was found between time spent on tasks and physician gender, age, years of practice, geographic location, practice type, contract type or weekly schedule (tables 8 and 9).

A negative association was found between time spent with tasks and patient list size. As the number of patients increases, the time spent on tasks decreases (minus $4.2 \mathrm{~s}$ for each increase of one patient-table 9).

No differences were found in the number of different tasks performed by gender, geographic location, practice type, contract type or weekly workload (table 8). Negative associations were found between the number 
Figure 1 Distribution of participating family physicians by region.

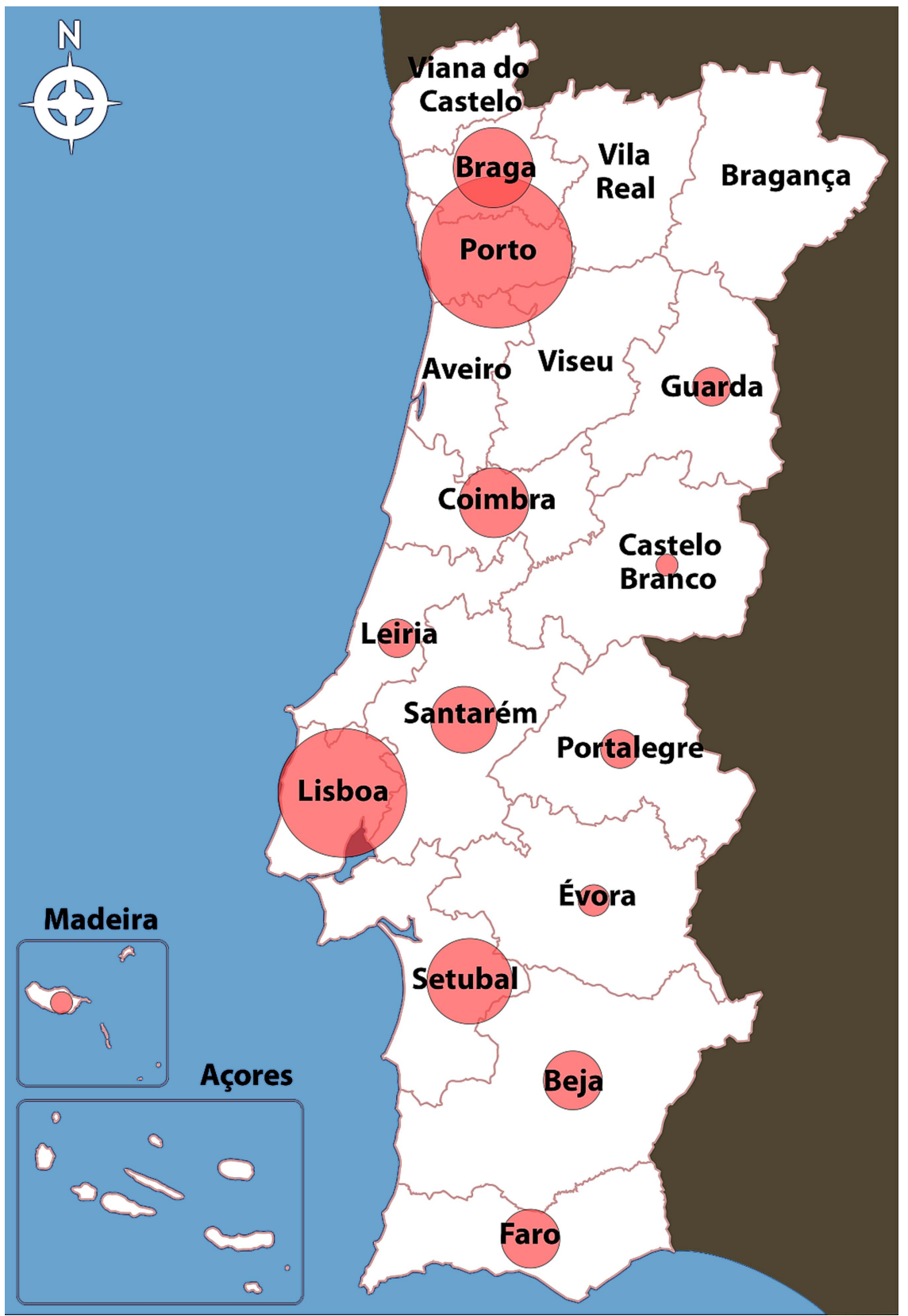

of different tasks performed and age, years of practice as an FP and patient list size. The number of different tasks performed decreases with increasing age, years of practice and list size (table 9). There were no associations found between these variables and time spent with more than one task simultaneously. No association was found between time spent with tasks and job satisfaction (table 9).

\section{DISCUSSION}

In this study of the workload of family doctors in Portugal, 155 FP spent a mean of $2 \mathrm{~h}$ and $20 \mathrm{~min} /$ day (33.4\% of their workday) performing tasks other than direct patient contact such as refilling prescriptions, teaching, attending meetings, managing the practice and communicating with other professionals about patients. Half of this time was spent on tasks which, although not face-to-face contacts, were related to specific patients. FP with larger patient lists spent significantly less time with these tasks. Older FP, with more seniority and larger lists, performed a significantly smaller range of tasks. Job satisfaction was not associated with time spent on non-patient contact tasks.

The main limitation of this study is the small sample size and the non-random sample. The 155 doctors participating on this study represent $2.8 \%$ of the $5503 \mathrm{FP}$ working in public primary care in Portugal. ${ }^{22}$ The small sample size was due to the difficulty in recruiting students and residents for data collection. The refusal rate for doctors was only $4.7 \%$. We do not know the reasons for the 39 data sets $(19.8 \%)$ never delivered by 
Table 4 Mean time spent (minutes) on daily activities by family physicians $(n=310)$

\begin{tabular}{|c|c|c|c|c|c|}
\hline Task & Mean & $95 \% \mathrm{Cl}$ & Minimum & Maximum & SD \\
\hline Tasks other than direct contact & 143.6 & 135.2 to 152.0 & 17 & 469 & 75.58 \\
\hline Related to patients & 73.0 & 68.0 to 77.9 & 1 & 243 & 44.59 \\
\hline Unrelated to patients & 74.3 & 67.2 to 81.3 & 0 & 364 & 63.37 \\
\hline Direct patient contacts & 278.2 & 267.1 to 289.4 & 47 & 622 & 100.25 \\
\hline Time per visit* $(n=243) \dagger$ & 15.9 & 15.2 to 16.7 & 3.7 & 47.9 & 6.08 \\
\hline House calls/other external work & 8.3 & 5.5 to 11.1 & 0 & 132 & 25.24 \\
\hline Effective daily working time $\ddagger$ & 430.1 & 416.5 to 443.7 & 124 & 722 & 122.22 \\
\hline Personal time & 57.6 & 52.3 to 62.9 & 0 & 289 & 47.38 \\
\hline
\end{tabular}

*Not including interruptions.

†Indirectly calculated, excluding days with over 30 min of data loss $(n=21)$ or with an unknown number of office visits $(n=46)$.

$\ddagger$ Effective work = tasks other than patient contact + office visits + house calls/other external services.

the student observers. This may have been due to non-explicit refusal to participate or to professional dissatisfaction.

In spite of sampling limitations, this is the first multicentric study of FP workload in Portugal with participants from all health regions in Continental Portugal. It used external observers which may provide more accurate data than that obtained by self-report. ${ }^{18} 19$

Our sample appears to be representative of Portuguese family medicine by age and location. The median age of participants was 54 years. In Portugal, $61.1 \%$ of FP are between 50 and 59 years of age. ${ }^{22}$ In our study, most of the participating FP work in the Northern Region and in the Lisbon and Tagus Valley Health Region, the most populous regions of the country with the most $\mathrm{FP}^{22}$

The inclusion of doctors involved in student and resident teaching may introduce another bias. They may have a wider task profile than non-academic colleagues. Also, data collection by multiple observers may

\begin{tabular}{|c|c|c|c|}
\hline & $\begin{array}{l}\text { Mean } \\
\text { (minutes) }\end{array}$ & $\begin{array}{l}\% \\
\text { workday* }\end{array}$ & $\begin{array}{l}\% \text { effective } \\
\text { workday }\end{array}$ \\
\hline Workday* & 498.7 & & \\
\hline Personal time & 57.6 & 11.6 & \\
\hline Missing data & 11.0 & 2.2 & \\
\hline $\begin{array}{l}\text { Effective working } \\
\text { time }\end{array}$ & 430.1 & 86.2 & \\
\hline $\begin{array}{l}\text { Direct patient } \\
\text { contacts }\end{array}$ & 278.2 & & 64.7 \\
\hline $\begin{array}{l}\text { Tasks other than } \\
\text { direct patient } \\
\text { contact }\end{array}$ & 143.6 & & 33.4 \\
\hline $\begin{array}{l}\text { House calls/ } \\
\text { other external } \\
\text { work }\end{array}$ & 8.3 & & 1.9 \\
\hline
\end{tabular}

*Workday = time between entering and exiting practice. $\dagger$ Effective workday $=$ tasks other than direct contact + office visits + house calls/other external work. introduce inter-observer bias, though this is inherent in studies using external observation of large samples of FP.

The mean time spent on tasks other than direct patient contact (over $11 \mathrm{~h}$ a week) is similar to the maximum protected time ever allocated in a contract to perform these tasks. Twelve hours per week were formerly allocated to some FP residency trainers with a 42-hour (per week) contract. Today, many FP have much less or no protected time. The figure of $33.4 \%$ of time devoted to non-patient contact tasks is higher than the finding in the previous study $(23 \%) .{ }^{10}$ The differences may be due to different methods of data collection, ${ }^{18}{ }^{19}$ changes in practice between 2010 and 2012 following reforms in Portuguese primary care or local conditions differing from findings in a national study.

Other studies using medical students for direct observation found similar proportions of time spent on nonpatient contact tasks, ranging from $29.1 \%$ in one study of $11 \mathrm{FP}^{11}$ to $39 \%$ in another study of $27 \mathrm{FP}^{12}$ Differences in the context of these studies may account for differences in the results. ${ }^{23}$ In Gilchrist's study, personal time and tasks relating to patients currently being seen in practice were included as non-patient contact tasks. ${ }^{12}$ Other published studies on this topic in primary care settings are more difficult to compare with our study, since they included primary care physicians other than family physicians such as internists and geriatricians. ${ }^{13-16}$

Studies performed in the USA found that more time was spent on tasks such as maintaining clinical records and on phone calls and e-mails to and from patients and their families. ${ }^{11-13} 15 \quad 17$ This may be explained by different systems of remuneration (eg, fee for service), depending on the medical acts recorded, by better facilities for telephone and e-mail contacts, and by a better non-medical to medical staff ratio. Student teaching may be over-represented in our study because of the sampling method chosen using student observers.

Half of the time spent on non-patient contact tasks was allocated to tasks that are directly related to patient care. This may ensure accessibility, continuity and coordination of care. ${ }^{89}$ 
Table 6 Time spent (in minutes) on tasks other than direct patient contact

\begin{tabular}{|c|c|c|c|c|c|}
\hline Task type & Mean & Max & Min & SD & $\mathbf{n}$ \\
\hline Prescription refills & 17.6 & 82 & 0 & 17.94 & 145 \\
\hline Student and resident teaching & 15.5 & 236 & 0 & 25.44 & 124 \\
\hline Practice meetings & 12.8 & 225 & 0 & 35.38 & 49 \\
\hline Practice management & 9.6 & 274 & 0 & 27.36 & 106 \\
\hline Administrative communication about patients & 8.6 & 54 & 0 & 9.32 & 144 \\
\hline Work preparation & 8.2 & 38 & 0 & 6.61 & 150 \\
\hline Clinical communication between professionals about patients & 7.8 & 62 & 0 & 9.89 & 133 \\
\hline Laboratory, imaging and other tests & 7.4 & 75 & 0 & 11.80 & 121 \\
\hline Pharmaceutical representatives & 7.3 & 122 & 0 & 15.30 & 88 \\
\hline Phone calls to and from patients & 6.3 & 50 & 0 & 8.20 & 131 \\
\hline Referrals & 6.2 & 113 & 0 & 14.03 & 94 \\
\hline Computer system malfunctions & 5.7 & 155 & 0 & 15.38 & 80 \\
\hline Clinical records & 4.8 & 57 & 0 & 10.06 & 87 \\
\hline Reports and certificates & 4.4 & 60 & 0 & 8.36 & 97 \\
\hline Continuing medical education & 4.0 & 95 & 0 & 15.51 & 26 \\
\hline Searches for clinical information & 3.1 & 51 & 0 & 6.89 & 82 \\
\hline Work phone calls unrelated to specific patients & 2.9 & 43 & 0 & 5.57 & 108 \\
\hline 'Corridor' conversations with patients/caregivers & 2.9 & 41 & 0 & 5.97 & 86 \\
\hline Work e-mails unrelated to specific patients & 2.4 & 45 & 0 & 5.83 & 66 \\
\hline Performance monitoring & 1.9 & 76 & 0 & 6.67 & 42 \\
\hline Restoring or replacing office supplies & 1.8 & 59 & 0 & 5.44 & 66 \\
\hline Case study, searching medical databases & 1.6 & 40 & 0 & 4.54 & 56 \\
\hline Others-related to specific patients & 1.5 & 54 & 0 & 5.54 & 52 \\
\hline Research & 1.1 & 44 & 0 & 4.98 & 22 \\
\hline E-mails to and from patients & 0.8 & 18 & 0 & 2.85 & 30 \\
\hline Helping colleagues & 0.7 & 26 & 0 & 2.70 & 35 \\
\hline Others-unrelated to specific patients & 0.4 & 18 & 0 & 1.80 & 27 \\
\hline
\end{tabular}

This population appears to spend little time on research. None of the previously published studies assessed time spent on clinical research. Research is essential to the development of family medicine as an academic and scientific discipline. In Portugal, many barriers to primary care research have been identified. Patient care is the priority and protected time for research is rare. ${ }^{24-27}$

Table 7 Job satisfaction of participating family physicians $(n=150)$

\begin{tabular}{|c|c|c|c|c|}
\hline $\begin{array}{l}\text { Job satisfaction } \\
\text { dimension }\end{array}$ & Mean & Maximum & Minimum & SD \\
\hline $\begin{array}{l}\text { Pressure and } \\
\text { demands at work }\end{array}$ & 2.5 & 4.6 & 1.0 & 0.68 \\
\hline Practice conditions & 3.7 & 5.0 & 1.0 & 0.86 \\
\hline Job interest & 4.0 & 5.0 & 2.5 & 0.49 \\
\hline Adequacy for work & 4.1 & 5.0 & 3.0 & 0.42 \\
\hline $\begin{array}{l}\text { Reward for the } \\
\text { work done }\end{array}$ & 3.1 & 4.7 & 1.0 & 0.73 \\
\hline $\begin{array}{l}\text { Interpersonal } \\
\text { relations and } \\
\text { autonomy }\end{array}$ & 4.2 & 5.0 & 2.3 & 0.61 \\
\hline Global & 3.5 & 4.6 & 2.3 & 0.37 \\
\hline
\end{tabular}

Communication with patients and their caregivers by electronic mail was rarely observed (less than $1 \mathrm{~min} /$ day), despite satisfaction with this means of contact among physicians and patients. ${ }^{28-30}$ Increased value for this medium in performance assessments may encourage its use. ${ }^{31-34}$

Interaction with pharmaceutical industry representatives occupied $7.8 \mathrm{~min}$ a day. In one Portuguese study, $82.7 \%$ of the FP stated that they used the pharmaceutical industry as a source of medical information. ${ }^{35}$ Information from pharmaceutical representatives may result in more prescriptions, use of more expensive drugs and prescription of lower quality. ${ }^{36}$ This finding suggests a need for reflection on these interactions occurring during working hours. ${ }^{37}$

Time spent on computer failures accounted for $5.7 \mathrm{~min}$ daily. This has not yet been studied in Portugal. Since clinical records, prescriptions, test ordering, referrals and certificates are all exclusively electronic, this problem is frequently cited as a source of physician dissatisfaction. ${ }^{38}$

Physicians saw a mean of 19 patients/day, similar to other studies. ${ }^{11}{ }^{12}$ However, those studies did not include indirect contacts such as prescription refills which averaged 6 per FP per day in our study, for a total of 25 patientrelated contacts recorded per FP per day.

Office visits lasted a mean of $15.9 \mathrm{~min} /$ patient in this study, similar to findings in other US studies of $\mathrm{FP}^{11} 12$ 
Table 8 Analysis of the association between time spent on tasks other than direct patient contact and of the total number of different tasks performed by demographic and professional characteristics of family physicians

\begin{tabular}{|c|c|c|c|c|c|c|}
\hline & \multicolumn{3}{|l|}{ Time with tasks } & \multicolumn{3}{|c|}{ Number of different tasks } \\
\hline & Mean (minutes) & SD & p Value* & Mean & SD & p Value* \\
\hline \multicolumn{7}{|l|}{ Sex } \\
\hline Female & 144.8 & 78.26 & \multirow[t]{2}{*}{0.6676} & 10.67 & 3.656 & \multirow[t]{2}{*}{0.3302} \\
\hline Male & 140.7 & 69.16 & & 11.09 & 2.708 & \\
\hline \multicolumn{7}{|l|}{ Practice type } \\
\hline Personalised Health Care Unit & 144.1 & 77.15 & \multirow[t]{2}{*}{0.9402} & 10.74 & 3.243 & \multirow[t]{2}{*}{0.8700} \\
\hline Family Health Unit & 143.4 & 75.18 & & 10.82 & 3.466 & \\
\hline \multicolumn{7}{|l|}{ Contract type } \\
\hline Individual public & 150.0 & 81.70 & \multirow[t]{2}{*}{0.7426} & 10.42 & 3.921 & \multirow[t]{2}{*}{0.5404} \\
\hline \multirow[t]{2}{*}{ Collective public } & 144.8 & 76.27 & & 10.85 & 3.332 & \\
\hline & Mean (minutes) & SD & p Valuet & Mean & SD & p Valuet \\
\hline \multicolumn{7}{|l|}{ Region } \\
\hline Alentejo & 139.2 & 72.87 & \multirow[t]{5}{*}{0.7579} & 10.89 & 2.487 & \multirow[t]{5}{*}{0.3131} \\
\hline Algarve & 126.4 & 77.37 & & 8.93 & 3.316 & \\
\hline Centre & 147.4 & 73.99 & & 10.57 & 3.382 & \\
\hline LTV and Madeira & 149.3 & 76.15 & & 10.98 & 3.825 & \\
\hline North & 139.8 & 76.40 & & 10.86 & 3.104 & \\
\hline \multicolumn{7}{|l|}{ Weekly schedule (contract hours) } \\
\hline 35 & 138.2 & 69.42 & \multirow[t]{4}{*}{0.7544} & 10.82 & 3.730 & \multirow[t]{4}{*}{0.9783} \\
\hline 40 & 145.0 & 75.79 & & 11.09 & 3.297 & \\
\hline 41 & 140.5 & 59.05 & & 11.00 & 2.944 & \\
\hline 42 & 149.0 & 80.48 & & 10.82 & 3.235 & \\
\hline $\begin{array}{l}\text { *Student's t test. } \\
\text { †ANOVA. } \\
\text { LTV, Lisbon and Tagus Valley. }\end{array}$ & & & & & & \\
\hline
\end{tabular}

and primary care internists ${ }^{14}$ and similar to findings in a previous Portuguese study $(14 \mathrm{~min}) .^{39}$ This probably underestimated the true value. The method used to determine time spent per office visit excluded interruptions to perform tasks not related to that specific visit. Furthermore, although FP were asked not to choose work days with residents working autonomously and seeing patients for them, it was found that this did

Table 9 Analysis of the association between time spent on tasks other than direct patient contacts and number of different tasks performed by age, years of practice, patient list size and job satisfaction

\begin{tabular}{lll}
\hline Independent variable & $\mathbf{p}$ Value & $\mathbf{9 5 \%} \mathbf{~ C l}$ \\
\hline $\begin{array}{l}\text { Time with tasks } \\
\text { Age }\end{array}$ & 0.161 & $(-1.45$ to 0.24$)$ \\
Years of service as a FP & 0.137 & $(-1.42$ to 0.20$)$ \\
Patient list size & $\mathbf{0 . 0 0 2}$ & $(-0.11$ to -0.02$)$ \\
FP's job satisfaction & 0.085 & $(-42.47$ to 2.76$)$ \\
Number of different tasks & & \\
Age & $\mathbf{0 . 0 2 1}$ & $(-0.079$ to -0.006$)$ \\
Years of practice as a FP & $\mathbf{0 . 0 0 5}$ & $(-0.084$ to -0.015$)$ \\
Patient list size & $\mathbf{0 . 0 1 1}$ & $(-0.004$ to -0.0006$)$ \\
\hline
\end{tabular}

Bold typeface indicates significance.

*Linear regression.

FP, family physician. happen. It is possible that some of the office visits performed by a resident have been recorded as under the FP's name. Finally, lost data were excluded from the total time spent at work while the number of office visits was taken from the electronic medical record.

Job satisfaction scores recorded here (3.5 of 5) were higher than those recorded (3.0) in a study conducted in the Lisbon Region in 2000. ${ }^{21}$ Organisational changes that have occurred in Portuguese primary care in the past 12 years may have increased satisfaction. In both studies, the dimension yielding the lowest score was 'pressure and demands at work'. The highest score was obtained in both for 'interpersonal relations and autonomy' and 'adequacy for the job'. ${ }^{21}$ A US study that assessed FP job satisfaction found an average score of 3.7 among primary care internists but carried out no further analysis. ${ }^{15}$

In our study, no association was found between job satisfaction and the time spent performing tasks. More time spent on tasks might decrease job satisfaction, since previous studies show lower job satisfaction to be associated with more time spent on administrative tasks. ${ }^{40}$ However, only half the total time for non-patient contact tasks was allocated to administration. The other half was given to clinical tasks. This may free more time for office visits, maximising time for direct interaction with the patient. With time pressure, FP have been found to ask less questions, to conduct less thorough clinical examinations and 
to gave less lifestyle advice. ${ }^{41}$ Longer visits may also result in fewer prescriptions, more preventive activities and increased advice on lifestyles. ${ }^{42}$ Physician satisfaction seems to increase with adequate visit length ${ }^{43}$ and to decrease with more time devoted to administrative tasks. ${ }^{40}$ A study of high-functioning primary care practices identified the shift to a shared-care model of work distribution and responsibility as one of the factors improving team functioning and satisfaction. This frees FP from tasks that do not require a physician but that may increase their burden. ${ }^{44}$ Job satisfaction is a 'buffer' against burnout. ${ }^{45}$ In Portugal, this has an estimated prevalence between $4.1 \%$ and $32.4 \% .{ }^{46}$ One explanation for the lower prevalence of burnout compared to other European countries is Portugal's high ratio of FP per inhabitant with smaller patient lists. ${ }^{46}$

A negative association was found between time spent on tasks other than direct patient care and patient list size. Increasing list sizes may increase pressure on office visits, reducing the time available for tasks that promote accessibility, continuity and coordination of care. Negative associations were also found between the number of different tasks performed and age, seniority and list size. With increasing age and seniority, FP may stop performing certain tasks, losing versatility and flexibility. Older FP, trained in older models of FM/GP practice, may not perform tasks other than direct patient contact. The ageing of Portuguese $\mathrm{FP}^{47}$ with changes in retirement laws and insufficient recruitment deserves attention.

In conclusion, time spent with tasks other than direct patient contact accounts for a third of the family doctor's workload. Half of this time is spent with tasks directly related to patient care, ensuring accessibility, continuity and coordination of care. These results show that the scope of tasks other than direct patient contact performed by FP in Portugal is consistent with the core features of Family Medicine/General Practice. These results should be taken into account when organising the FP working day. The inverse relationships between time spent with these tasks and list size and age deserve close monitoring.

Acknowledgements The authors would like to thank the following medical students and family medicine residents who volunteered for data collection (as well as those who do not wish to be mentioned): Albina Hora Moreira, Albina Maria Oliveira, Ana Antónia Cunha, Ana Carolina Abreu, Ana Catarina Vieira, Ana Cláudia Pereira, Ana Costa Mano, Ana Daniela Silva, Ana Esteves, Ana Luísa Bernardo, Ana Luísa Gomes, Ana Luísa Poças, Ana Luísa Reis, Ana Margalha Miranda, Ana Nunes Barata, Ana Patrícia Alves, Ana Rita Andrade, Ana Rita Marques, Ana Sofia Peixoto, Anaísa Silva, Andréa Antunes, Andreia Castro, Ângela Soares, António Carvalho, Beatriz Pavão Braga, Bernardo Barata, Bernardo Costa Neves, Bruno Melo, Carina Pereira, Carla Martins, Carla Ribeiro, Carla Simão, Carlota Cavazza, Carolina Gomes Moreira, Carolina Marini, Carolina Teixeira, Catarina Bessa, Catarina Neto Pereira, Catarina Palmeira, Catarina Silva Nunes, Cátia Pereira, Cátia Sapateiro, Célia Sousa Maia, Cláudia Lourenço, Cláudia Matos, Cláudia Teixeira, Dalila Costa, Daniela Amaral, Daniela Las Casas, Dário Perdigão, Diana Martins Correia, Diana Repolho, Diogo Abel Pinto, Diogo Santos Lopes, Diogo Semedo, Edgar Moreira, Eduardo Ventura, Emanuel Raposo, Fabiana Peixoto, Fani Ribeiro, Fernanda Vilela, Filipa Ferro, Filipa Loureiro Neves, Filipa Pedrosa, Filipa Quinteiros, Filipa Reis, Filipe Benito Garcia, Frederico Trigueiros, Gabriel Almeida, Gilberto Guimarães, Gisela Lima, Guilherme Pereira, Helena
Nascimento, Helena Vasconcelos, Hugo Afonso, Inês Carvalho, Inês Galveias, Inês Gama, Isabel Solha, Joana Araújo, Joana Carneiro, Joana Elisa Torre, Joana Ferreira, Joana Lote, Joana Oliveira, Joana Simões Casanova, Joana Soares, João Nuno Freixo, João Pedro Dias, João Ribeiro, João Veigas Abrantes, Joaquim Dores, Joaquim Lima, José Pedro Azevedo, Laura Magalhães Gonçalves, Laura Viegas, Lucélia Campino, Luciana Paulo, Luís Morais, Mafalda Felgueiras, Magda Simões, Mara Marques, Marco Bernardes, Marco Menezes, Margarida Ferreira, Margarida Moreira, Margarida Romão, Maria Inês Oliveira, Maria João Lopes, Maria Sá Soares, Maria Teresa Santos, Mariana Afonso, Mariana Cruz Alves, Mariana Gayo, Mariana Oliveira, Marta Barroca, Marta Cunha, Marta Ezequiel, Melissa Fernandes, Miguel Bigotte Vieira, Miguel Ferreira, Nádia Marinho, Nelson Peixoto Oliveira, Nuno Cordeiro Simões, Nuno Fonseca, Patrícia Amaral, Paulo Santos, Pedro Cubelo Pereira, Pedro Veiga, Punit Naguindás, Raquel Almeida Dias, Raquel Henriques, Ricardo Almeida Oliveira, Rita Homem, Rita João Gonçalves, Rita Pocinho, Rui Assis, Rui Buzaco, Sandra Filipa Silva, Sandra Serrão, Sara Cunha, Sara Malta Vacas, Sara Rocha, Sara Silva, Sérgio Gomes Pereira, Sílvia Alves Torres, Sónia Martins Santos, Susana Ferreira, Tiago Guedes, Tiago Pack, Vânia Fernandes Teixeira, Vera Clérigo, Vera Juliana Costa, Verónica Pavão Borges e Virgínia Sousa. The authors would also like to thank the following participating FP (as well as those who do not wish to be mentioned): Alexandra Abrunhosa, Alfredo Couto, Alzira Pereira, Ana Cavaleiro, Ana Isabel Campos, Ana Isabel Lourenço, Ana Lopes Gomes, Ana Lúcia Vaz, Ana Maria Almeida, Ana Maria Costa, Ana Maria Lorena, Ana Nicolau Gomes, Ana Paula Lemos, Ana Paula Quaresma, Ana Paula Reis, Ana Paula Tavares, Ana Rita Mourão, Ana Rodrigues, Antoni Jiménez Garcia, António Filipe, António Frazão, António Matos, António Nave Ferreira, António Nunes Lopes, António Rangel, António Sameiro Correia, Armando Brito de Sá, Arménio Ramos, Artur Sirbu, Benilde Heitor, Cândido Macedo, Carla Morna, Carla Silva, Carlos Alberto Carvalho, Carlos Canhota, Carlos Príncipe Ceia, Carmo Novais, Catarina Betencourt, Célia Isidoro Pinheiro, Célia Santos, Celina Peliz, Cláudia Santos Silva, Conceição Costa, Conceição Outeirinho, Cristina Lopes, Cristina Ramos, Cristina Rodrigues, Darcília Eusébio, Dília Sameiro Correia, Dinis Brito, Edmundo Sá, Eduarda Abreu e Lima, Eugénia Pereira, Eugénia Silva, Fátima Saraiva, Fernando Freire, Flamínia Cidrais, Guilherme Ferreira, Helena Antunes, Helena Ferreira, Hermínia Nascimento, Inês Bacelar, Inês Maio, Inês Silva, Irene Martins, Isabel Sá Pereira, Jaime Cavadas, Joana Cabrita, Joana Campina, João Arcanjo, João Carvalho, João Cocharra, João Ramires, Jorge Madeira, Jorge Rocha de Almeida, José Albino Mesquita, José Augusto Simões, José Farinha, José Manuel Feliz, José Manuel Nápoles, José Manuel Sousa, José Miguel Coutinho, Judith Armas, Júlio Crespo Silva, Justina Silva, Laurinda Leitão, Lineu Palmeira, Luís Ribeiro, Luísa Quaresma, Luísa Sousa Santos, Mafalda Ribeiro, Magda Santos, Manuel Santos Soares, Manuela Ambrósio, Manuela Dias, Manuela Graça, Márcia Braga, Margarida Leite, Margarida Lobão, Maria Antonieta Teixeira, Maria Cristina Morgado, Maria Helena Filipe, Maria Jesus Clara, Maria João Martins, Maria João Queiroz, Maria Luísa Valga, Maria Manuela Duarte, Maria Rosário Martins, Marta Marquês, Miguel Cerqueira, Mónica Mozes, Noémia Pinto, Patrícia Valadares, Paula Assunção, Paula Costa, Paula Oliveira, Pedro Lopes Guimarães, Pedro Pablo Jimenez, Pedro Salgado Gomes, Rita Ferreira, Rita Viegas, Rosa Gallego, Rosa Tomás, Rui Garcia, Rui Guedes, Salomé Sousa Coutinho, Sara André, Sofia Norte, Susana Paiva, Susana Ribeira, Teresa Alves, Teresa Antunes, Teresa Carneiro, Teresa De Santis, Teresa Febra, Teresa Filipe, Teresa Gomes, Teresa Libório, Teresa Rodrigues, Teresa Ventura, Tony Garcês Andrade, Valério Capaz, Vanda Proença, Vanessa Aires, Yolanda Carollo, Yvan Serandão Rodrigues e Zélia Godinho. The authors would also like to thank the seven Portuguese medical schools (and especially their family medicine departments) and the family medicine regional residency coordinators who cooperated in study recruitment. The authors wish to thank John Yaphe for editorial assistance.

Contributors The authors state that MG, CP and LFC were responsible for the conception, design, collaborator and participant recruitment and data analysis. $M G$ and $C P$ wrote the article. All authors have given their final approval of the version to be submitted.

Funding The submitted work was funded by a grant of $1.700 €$ from the Ministry of Health, through the National Institute of Health (Instituto Nacional de Saúde Doutor Ricardo Jorge). The grant was won by submission of the study protocol to a national contest in 2011. The funding was used to cover 
costs for paper stationery, posts, contacts with medical schools which helped find external observers for the study and statistical consulting. Study sponsors had no role in designing the protocol, collecting data, analysing results, discussing them or reviewing the manuscript. Researchers, external observers and participants were totally independent from the funders.

Competing interests None.

Ethics approval The study protocol was ethically approved by the two main independent review boards in Portuguese primary care in 2011 (North and Lisbon and Tagus Valley Regional Health Administrations independent review boards). The two files are uploaded with the manuscript.

Provenance and peer review Not commissioned; externally peer reviewed.

Data sharing statement Extra data are available by emailing MG (monica. granja@ulsm.min-saude.pt).

Open Access This is an Open Access article distributed in accordance with the Creative Commons Attribution Non Commercial (CC BY-NC 3.0) license, which permits others to distribute, remix, adapt, build upon this work noncommercially, and license their derivative works on different terms, provided the original work is properly cited and the use is non-commercial. See: http:// creativecommons.org/licenses/by-nc/3.0/

\section{REFERENCES}

1. Richardson WC, Berwick DM, Bisgard JC, et al. Committee on Quality Health Care, Institute of Medicine. Crossing the quality chasm: a new health system for the 21st century. Washington, DC National Academy Press, 2001. http://books.nap.edu/html/quality chasm/reportbrief.pdf (accessed 1 Dec 2010).

2. Haggerty JL, Pineault R, Beaulieu MD, et al. Practice features associated with patient-reported accessibility, continuity, and coordination of primary health care. Ann Fam Med 2008;6:116-23.

3. Gérvas J, et al. El debate profesional acerca de la escasez de médicos. Rev Esp Salud Pública 2008;82:627-35.

4. Davis K, Schoenbaum SC, Audet AM. A 2020 vision of patient-centered primary care. J Gen Intern Med 2005;20:953-7.

5. Baleiras SJ, Ramos V. A Gestão da Prática Clínica pelo Médico de Família. Rev Port Clin Ger 1992;9:116-24.

6. Decreto-Lei n. ${ }^{\circ} 176 / 2009$, de 4 de Agosto. Diário da República, $1^{\text {a }}$ série-N. ${ }^{\circ} 149,5043-7$

7. Decreto-Lei n. ${ }^{\circ} 177 / 2009$, de 4 de Agosto. Diário da República, $1^{\text {a }}$ série-N. ${ }^{\circ} 149,5047-53$.

8. Bodenheimer T. Coordinating care-a perilous journey through the health care system. N Engl J Med 2008;358:1064-71.

9. Bodenheimer T. Coordinating care: a major (unreimbursed) task of primary care. Ann Intern Med 2007;147:730-1.

10. Granja M, Ponte C. O que ocupa os médicos de família? Caracterização do trabalho médico para além da consulta. Rev Port Clin Geral 2011;27:388-96.

11. Gottschalk A, Flocke SA. Time spent in face-to-face patient care and work outside the examination room. Ann Fam Med 2005;3:488-93.

12. Gilchrist V, McCord G, Schrop SL, et al. Physician activities during time out of the examination room. Ann Fam Med 2005;3:494-9.

13. Farber J, Siu A, Bloom P. How much time do physicians spent providing care outside of office visits? Ann Intern Med 2007;147:693-8.

14. Baron J. What's keeping us so busy in primary care? A snapshot from one practice. N Engl J Med 2010;362:1632-6.

15. Chen MA, Hollenberg JP, Michelen W, et al. Patient care outside of office visits: a primary care physician time study. J Gen Intern Med 2011;26:58-63.

16. Doerr E, Galpin K, Jones-Taylor C, et al. Between-visit workload in Primary Care. J Gen Intern Med 2010;25:1289-92.

17. Jacobson CJ Jr, Bolon S, Elder $\mathrm{N}$, et al. Temporal and subjective work demands in office-based patient care: an exploration of the dimensions of physician work intensity. Med Care 2011;49:52-8.

18. Bratt JH, Foreit J, Chen PL, et al. A comparison of four approaches for measuring clinician time use. Health Policy Plann 1999;14:374-81.

19. Finkler SA, Knickman JR, Hendrickson G, et al. A comparison of work-sampling and time-and-motion techniques for studies in health services research. Health Serv Res 1993;28:577-97.

20. Biscaia A. A satisfação no trabalho dos médicos de família dos centros de saúde portugueses. [Tese de Doutoramento]. Lisboa: Instituto de Higiene e Medicina Tropical, 2010.
21. Biscaia A. Futurar em Positivo-Satisfação no Trabalho. Sintra: Grafisol-Edições e Papelarias, Lda, 2013.

22. Administração Central do Sistema de Saúde. Inventário de Pessoal do Sector da Saúde. 2012. http://www.acss.min-saude.pt/Portals/0/ Invent\%C3\%A1rio_vf.pdf (accessed 27 Oct 2013).

23. Gérvas J. Atención Primaria de Salud en Europa: tendencias a principios del siglo XXI. Una reflexión con motivo de los XXV años de la Declaración de Alma Ata. SEMERGEN-Medicina de Familia 2004;30:245-57.

24. Santos I. Não seremos competitivos na investigação com os internatos distantes da academia. MGF Notícias 2013 Outubro 15 Entrevista: 12-14.

25. Braga R. A necessidade de nos afirmarmos na investigação. Rev Port Clin Geral 2011;27:257-8.

26. Santos I. Precisamos investir na investigação. Rev Port Clin Geral 2003;19:395-6.

27. van der Zee J, Kroneman M, Bolíbar B. Conditions for research in general practice. Can the Dutch and British experiences be applied to other countries, for example Spain? Eur J Gen Pract 2003;9:41-7.

28. Gaster B, Knight CL, DeWitt DE, et al. Physician's use and attitudes toward electronic mail for patient communication. J Gen Intern Med 2003;18:385-9.

29. Leong SL, Gingrich D, Lewis PR, et al. Enhancing doctor-patient communication using email: a pilot study. J Am Board Fam Pract 2005;18:180-8.

30. Liederman EM, Lee JC, Baquero VH, et al. Patient-physician web messaging: the impact on message volume and satisfaction. $J$ Gen Intern Med 2005;20:52-7.

31. Ponte C. A utilização do correio electrónico na comunicação com os utentes da USF Porta do Sol. Rev Port Clin Geral 2011;27:274-80.

32. Granja M. O uso do e-mail na comunicação com o médico de família: catorze meses de experiência. Rev Port Clin Geral 2009;25:639-46.

33. Car J, Scheikh A. Email consultations in health care: a 2-acceptability and safe application. BMJ 2004;329:439-42.

34. Bergmo T, Wangberg C. Patients' willingness to pay for electronic communication with their general practitioner. Eur $J$ Health Econ 2007:8:105-10.

35. Santiago LM. Fontes de informação sobre medicamentos em Clínica Geral/Medicina Geral e Familiar. Rev Port Clin Geral 2006;22:689-98.

36. Spurling Gk, Mansfield PR, Montgomery BD, et al. Information from pharmaceutical companies and the quality, quantity, and cost of physicians' prescribing: a systematic review. PLoS Med 2010;7 e1000352.

37. Ministério da Saúde. Despacho n ${ }^{\circ} 8213-B / 2013$ Diário da República, 2. ${ }^{a}$ série-N. ${ }^{\circ} 119-24$ de junho de 2013.

38. Pedro TL. Médicos denunciam caos no sistema informático da saúde. Público 2013. http://www.publico.pt/sociedade/noticia/ medicos-denunciam-caos-no-sistema-informatico-da-saude-1597717 (accessed 15 Nov 2013).

39. Miranda JA, Aguiar PV. Carga de trabalho, uso do tempo prescrição de antibióticos e referenciação em consulta de Clínica Geral. Rev Port Clin Geral 1997;14:377-86.

40. Grembowski D, Ulrich CM, Paschane D, et al. Managed care and primary physician satisfaction. J Am Board Fam Pract 2003:16:383-93.

41. Tsiga E, Panagopoulou E, Sevdalis N, et al. The influence of time pressure on adherence to guidelines in primary care: an experimental study. BMJ Open 2013;3:e002700.

42. Wilson $A$, Childs $S$. The relationship between consultation length, process and outcomes en general practice: a systematic review. $\mathrm{Br} J$ Gen Pract 2002;52:1012-20.

43. Probst JC, Greenhouse DL, Selassie AW. Patient and physician satisfaction with an outpatient care visit. J Fam Pract 1997;45:418-25.

44. Sinsky CA, Willard-Grace R, Schutzbank AM, et al. In search of joy in practice: a report of 23 high-functioning primary care practices. Ann Fam Med 2013;11:272-8.

45. Visser MR, Smets EM, Oort FJ, et al. Stress, satisfaction and burnout among Dutch medical specialists. CMAJ 2003;168:271-5.

46. Marcelino G, Cerveira JL, Carvalho I. Burnout levels among Portuguese family doctors: a nationwide survey. BMJ open 2012;2:e001050.

47. Santana $\mathrm{P}$, Peixoto $\mathrm{H}$, Loureiro A, et al. Estudo de Evolução Prospectiva de Médicos no Sistema Nacional de Saúde-relatório final. Universidade de Coimbra, 2013. http://www.nortemedico.pt/ download.php?path=pdf\&filename=SRNOM 20130918162117 Estudo_Evolucao_Prospectiva_Medicos_Relatorio_Final.pdf (accessed 21 Sep 2013) 